\title{
ARTICLE
}

\section{Competitive formation of DNA linkage isomers by a trinuclear platinum complex and the influence of pre-association}

Cite this: DOI: $10.1039 /$ xoxxooooox

\author{
Joseph J. Moniodis, ${ }^{\llbracket a}$ Donald S. Thomas, ${ }^{\uparrow+a}$ Murray S. Davies, ${ }^{\ddagger a}$ Susan J. Berners- \\ Price $^{* a, b}$ and Nicholas P. Farrell ${ }^{* c, b}$
}

Received ooth January 2012, Accepted ooth January 2012

DOI: $10.1039 / \times 0 x x 00000 x$

www.rsc.org/
2D $\left[{ }^{1} \mathrm{H},{ }^{15} \mathrm{~N}\right]$ HSOC NMR spectroscopy has been used to monitor the reaction of fully ${ }^{15} \mathrm{~N}$-labelled [ $\{$ trans$\left.\operatorname{PtCl}\left(\mathrm{NH}_{3}\right)_{2}\right\}_{2}\left(\mu\right.$-trans-Pt $\left.\left.\left(\mathrm{NH}_{3}\right)_{2}\left\{\mathrm{NH}_{2}\left(\mathrm{CH}_{2}\right)_{6} \mathrm{NH}_{2}\right\}_{2}\right)\right]^{4^{+}} \quad\left(\mathrm{BBR} 3464 \quad\left({ }^{15} \mathrm{~N}-1\right)\right)$ with the 14-mer duplex (5'$\left\{\mathrm{d}\left(\right.\right.$ ATACATG(7)G(8)TACATA)\}-3' $\cdot 5^{\prime}-\{\mathrm{d}(\mathrm{TATG}(18) T A C C A T G(25) T A T)\}-3^{\prime}$ or I) at pH 5.4 and $298 \mathrm{~K}$, to examine the possible formation of 1,4 and $1,5-G G$ adducts in both $5^{\prime}-5^{\prime}$ and $3^{\prime}-3^{\prime}$ directions. In a previous study, the binding of the dinuclear $1,1 / t, t$ to I showed specific formation of the $5^{\prime}-5^{\prime} 1,4$ $G(8) G(18)$ cross-link, whereas in this case a mixture of adducts were formed. Initial ${ }^{1} \mathrm{H}$ NMR spectra suggested the presence of two pre-associated states aligned in both directions along the DNA. The preassociation was studied in the absence of covalent binding, by use of the "non-covalent" analog [\{trans$\left.\operatorname{Pt}\left(\mathrm{NH}_{3}\right)_{3}\right\}_{2}\left(\mu\right.$-trans-Pt $\left.\left.\left(\mathrm{NH}_{3}\right)_{2}\left\{\mathrm{NH}_{2}\left(\mathrm{CH}_{2}\right)_{6} \mathrm{NH}_{2}\right\}_{2}\right)\right]^{6+}\left(\mathrm{AH}_{44}\right.$, 0$)$. Chemical shift changes of DNA protons combined with $\mathrm{NOE}$ connectivities between $\mathrm{CH}_{2}$ and $\mathrm{NH}_{3}$ protons of $\mathrm{o}$ and the adenine $\mathrm{H} 2$ protons on I show that that two different molecules of $\mathrm{o}$ are bound in the minor groove. Molecular dynamic simulations were performed to study the interaction of $o$ at the two pre-association sites using charges derived from density functional theory (DFT) calculations. Structures where the central platinum is located in the minor groove and the aliphatic linkers extend into the major groove, in opposite directions, often represent the lowest energy structures of the snapshots selected. In the reaction of ${ }^{15} \mathrm{~N}-1$ and $\mathrm{I}$, following the pre-association step, aquation occurs to give the mono aqua monochloro species 2, with a rate constant of $3.43 \pm 0.03 \times 10^{-5} \mathrm{~s}^{-1}$. There was evidence for two monofunctional adducts $(3,4)$ bound to the $3^{\prime}(G 8)$ and $5^{\prime}\left(G_{7}\right)$ residues and the asymmetry of the ${ }^{1} \mathrm{H}_{1}{ }^{15} \mathrm{~N}$ peak for 3 suggested two conformers of the $3^{\prime}$ adduct, aligned in different directions along the DNA. The rate constant for combined monofunctional adduct formation $\left(0.6 \pm 0.1 \mathrm{M}^{-1}\right)$ is ca. 2-fold lower for 1 compared to $1,1 / t, t$, whereas the rate constant for conversion of the combined monofunctional species to combined bifunctional adducts $(5)\left(8.0 \pm 0.2 \times 10^{-5} 5^{-1}\right)$ is two-fold higher.

\section{Introduction}

The targeting of DNA has played a significant role in the development of the current anticancer drug armamentarium. ${ }^{1,2}$ New molecular mechanisms are identified by which small molecules recognize or interact with DNA, which remains a clinically important target. $^{1}$ One such class of potential anticancer agents with a unique mode of DNA binding is that of polynuclear platinum complexes, as exemplified by the clinically relevant trinuclear $\left[\left\{\text { trans-PtCl }\left(\mathrm{NH}_{3}\right)_{2}\right\}_{2}(\mu\right.$-trans$\left.\left.\mathrm{Pt}\left(\mathrm{NH}_{3}\right)_{2}\left\{\mathrm{NH}_{2}\left(\mathrm{CH}_{2}\right)_{6} \mathrm{NH}_{2}\right\}_{2}\right)\right]^{4+} \quad(B B R 3464$, Triplatin (1) or $1,0,1 / t, t, t)$ (Chart 1$)$. Given the role of DNA repair in clinical resistance to cisplatin, cellular processing of structurally discrete Pt-DNA adducts may also be reflected in a different profile of biological and anticancer activity. ${ }^{3}$

BBR3464-DNA interactions are distinct from the mononuclear cisplatin and oxaliplatin and, indeed, unlike those of any agent in clinical use. Long-range interstrand crosslinks
(IXLs) occur not only in the "normal" 5'-5' direction, since DNA is normally read from the $5^{\prime}$-side, but also in the "'opposite", antiparallel 3 '-3' direction, ${ }^{4}$ to our knowledge the only such well-described example. ${ }^{5}$ Complementary molecular biology and spectroscopic approaches showed that both crosslinks occur as a pair of conformers and that all four conformers affect DNA in a distinctly different way. ${ }^{6}$ 2D $\left[{ }^{1} \mathrm{H},{ }^{15} \mathrm{~N}\right]$ HSQC NMR Spectroscopy using fully- ${ }^{15} \mathrm{~N}$ labelled BBR3464 and the duplex 12-mer $5^{\prime}$-d(ATATGTACATAT)2 (II) $\left(5^{\prime}-5^{\prime}\right.$ between $\mathrm{G}$ and the $\mathrm{G}$ of complementary $\mathrm{C}$ ) confirmed formation of two distinct, non-interconvertible conformers. $^{7}$ In contrast, studies with 5'd $\{\text { TATACTAGTATA }\}_{2}$ (III) (now $3^{\prime}-3^{\prime}$ ) showed that the preassociation and aquation steps were similar but the reaction did not yield a single distinct $1,4-G G$ IXL, and numerous crosslinked adducts formed. ${ }^{8}$ Molecular dynamics simulations showed a highly distorted structure with fraying of the end base pairs and considerable widening of the minor groove. ${ }^{8}$ The 
results suggest that the multiple DNA cross-links available to BB3464 may all contribute substantially to its cytotoxicity, so that the overall drug cytotoxicity could be the sum of the contributions of different interstrand and intrastrand adducts.

Pre-association on DNA through electrostatic and hydrogen bonding occurs prior to covalent binding of BBR3464, and may influence the directionality of the crosslink formation. ${ }^{7}$ To examine only pre-association in absence of Pt-DNA bond formation, a series of high-affinity "non-covalent" compounds were prepared by substitution of $\mathrm{Cl}^{-}$with either $\mathrm{NH}_{3}$ (AH44 (0)) or a "dangling amine" (TriplatinNC) where one end of the diamine is linked to Pt with the other end free and protonated, Chart 1 . The X-ray crystal structure of the Dickerson-Drew Dodecamer, (DDD, [d(CGCGAATTCGCG) $]_{2}$ ) with the noncovalent compounds has delineated a new mode of ligand-DNA recognition distinct from the conventional modes of intercalation and groove binding. ${ }^{9}, 10$ Hydrogen bonding with phosphate oxygens results in either backbone tracking or minor groove spanning through formation of "phosphate clamps" (Chart 1) where the square-planar tetra-am(m)ine $\mathrm{Pt}(\mathrm{II})$ coordination units all form bidentate N-O-N complexes with phosphate oxygen OP atoms. In both cases, the conformation in the DDD-Phosphate Clamp complexes differs significantly from that of the native structure (NDB entry bdl084).

In agreement with the solid-state studies, the central "noncovalent" platinum moiety of BBR3464 resides in or near the minor groove when the complex forms a 1,4-GG IXL with an 8-mer DNA sequence. ${ }^{11}$ The interactions of AH44 (0, Chart 1) with the self-complementary duplex d(GGTAATTACC)2, a "high-affinity" sequence for minor groove binders such as Hoechst 33258, showed the largest chemical shift perturbations consistent with the ligand being located at the centre of the AATT binding site. ${ }^{12}$

Previous studies have examined the effects of preassociation on crosslink directionality using site-specific sequences designed to produce either a $5^{\prime}-5^{\prime}$ or $3^{\prime}-3^{\prime}$ isomer. In this paper we chose a 14-mer sequence providing four possible modes of binding since it contains two $G$ bases on each strand (5'-\{d(ATACATGGTACATA $)\}-3 ' \quad$. 5'$\{$ d(TATGTACCATGTAT) $\}-3$ ' or I). The binding of the dinuclear species $1,1 / t, t$ to this sequence showed specific formation of the $5^{\prime}-5^{\prime}$ 1,4 IXL, between G8 and G18. ${ }^{13}$ This work is an extension of the previous study, attempting to determine the binding mode of BBR3464 and whether the trinuclear compound indeed does bind in both directions and the nature of this binding. The stepwise formation of the bifunctional lesion is illustrated in Scheme 1, showing the four possible GN7-GN7 IXLs that can be formed with duplex I, assuming that both 1,4 and 1,5-GG adducts are possible in both $5^{\prime}-5^{\prime}$ and $3^{\prime}-3^{\prime}$ directions. We also examine the role of the charged central linker and the pre-association process in determining the DNA binding mode.

\section{Results}

The reaction of ${ }^{15} \mathrm{~N}-\mathbf{1}$ with duplex $\mathbf{I}$ was followed using ${ }^{1} \mathrm{H}$ and 2D $\left[{ }^{1} \mathrm{H},{ }^{15} \mathrm{~N}\right] \mathrm{HSQC}$ and ${ }^{1} \mathrm{H}$ NMR spectroscopy by the same NMR approach that we have used previously to study the kinetics of mechanism of interstrand crosslinking of ${ }^{15} \mathrm{~N}-1$ with different defined DNA duplexes. ${ }^{7,}$ 8, 14 To allow for direct comparison with previous studies (and particularly the reaction of $1,1 / t, t$ with duplex $\mathbf{I})^{13}$ similar conditions were chosen $(\mathrm{pH}$ 5.4, $298 \mathrm{~K})$. The ${ }^{1} \mathrm{H}$ NMR spectra recorded immediately after addition of $\mathbf{1}$ to duplex $\mathbf{I}$ showed splitting in the G7, G18 and G25 imino proton resonances (Fig. 1), suggesting the presence of two pre-associated states aligned in both directions along the DNA.

\section{Pre-covalent Binding Step. Comparing 0 to 1}

To study the pre-association step in detail in the absence of covalent binding, we utilised the "non-covalent" analog $\mathbf{0}$. Density functional theory calculations have shown that the differences in charge between 1 (4+) and $\mathbf{0}(6+)$ are largely confined to the ends of the molecule and the charge distribution of the central platinum linker is similar for both complexes. ${ }^{15}$ Given that the charge on the central $\left\{\mathrm{PtN}_{4}\right\}$ unit is the most important contributor to pre-association ${ }^{7}$ then $\mathbf{0}$ is a reasonable model to study the pre-association step for $\mathbf{1}$.

${ }^{1} \mathrm{H}$ NMR spectra (at $298 \mathrm{~K}$ ) were recorded for a solution of duplex I in the presence of $\mathbf{0}$ (2:1 ratio). Chemical shift changes of assignable DNA protons upon addition of the complex have been examined and an assignment Table is presented in the supporting information. The chemical shift changes for the H6/H8 protons are generally very slight $(\Delta \delta \leq$ 0.05 ), with the greatest change occurring for G8 H8 and C11 $\mathrm{H} 6(\Delta \delta=0.05)$. For the $\mathrm{H}^{\prime}{ }^{\prime}$ resonances, the greatest chemical shift change is observed for the $\mathrm{C} 22$ base $(\Delta \delta=-0.15)$ with notable changes also for the T9 $(\Delta \delta=-0.12)$, T19 $(\Delta \delta=-0.11)$ and G7 $(\Delta \delta=-0.10)$ bases. Significant changes were also observed for the T9 and T19 H2" protons $(\Delta \delta=-0.11$ and 0.14 , respectively). Of the imino protons, those of the T24 A5 $(\Delta \delta=-0.12)$ and T26 A3 $(\Delta \delta=0.12)$ base pairs shifted most notably, with smaller changes observed for three of the four GC base pairs: G7 C22 ( $\Delta \delta=0.08), \mathrm{G} 18 \mathrm{C} 11$ and G25 C4 $(\Delta \delta=$ $0.05)$, consistent with observation in the reaction of $\mathbf{1}$ and $\mathbf{I}$ (Fig. 1). For the adenine $\mathrm{H} 2$ protons, the greatest chemical shift changes are observed for $\mathrm{A} 10(\Delta \delta=0.20)$ and $\mathrm{A} 20(\Delta \delta=0.18)$. The large variation of chemical shift of T26 H1', along with changes in the chemical shifts of A10 and A20 H2 protons, is consistent with the possibility of two binding sites at either end of the centre of the DNA sequence. This possibility is further supported by large changes in the T9 and T19 H2" protons, and is consistent with the 2:1 complex:DNA ratio.

NOE connectivities between the $\mathrm{CH}_{2}$ and $\mathrm{NH}_{3}$ protons of $\mathbf{0}$ and the adenine $\mathrm{H} 2$ and $\mathrm{C} 22 \mathrm{H} 6$ protons on $\mathbf{I}$ were observed in the $298 \mathrm{~K}{ }^{1} \mathrm{H}$ NOESY NMR spectrum (Fig. 2). The connectivities (Fig. 3) are primarily to the adenine $\mathrm{H} 2$ protons (A3, A5, A10, A12, A16, A20, A23 and A27), indicative of binding in the minor groove. The observation of connectivities along the whole DNA sequence, combined with the large 
chemical shift changes of the T26 H1', A10 and A20 H2 protons is further evidence that two different molecules of $\mathbf{0}$ are bound in the minor groove of $\mathbf{I}$. The observed NOE connectivities indicate that in the two different binding sites the central platinum moiety is located between the A3 and A5 bases (x) and near the A10 base (y) (Fig. 3). The two sites are termed the G25 site and the G18 site, respectively.

\section{Molecular Modelling. Pre-covalent Binding Step}

10 ns of production dynamics were performed on $\mathbf{0}$ with $\mathbf{I}$ to compare with the NMR results and to examine the preassociation process in further detail. Simulations were performed to study the interaction of $\mathbf{0}$ at the G18 and G25 preassociation sites. For each site simulations were performed using charges derived from density functional theory (DFT) calculations. $^{15}$ Snapshots of various time points in the productions dynamics simulations are shown in Fig. 4 and the energies of the minimised structures from the snapshots are provided in the supporting information.

The production dynamics simulation at the G18 site employing DFT charges lasted 10.67 ns. In the lowest energy snapshot of this simulation (1631 - 1660 ps) the central platinum, along with one aliphatic linker and its terminal $\left\{\mathrm{PtN}_{4}\right\}$ moiety are located in the minor groove with the other linker extending around the phosphate backbone into the major groove. For the majority of the simulation, the central platinum and at least one aliphatic linker and its terminal $\left\{\mathrm{PtN}_{4}\right\}$ group are in the minor groove. The widest minor groove width (14.7 A) occurs at the T9/A10 base pair step, whilst the G7/G8 base pair step (two steps away from the widest point) has the narrowest minor groove width. The complex remains in, or close to, the minor groove for the majority of the simulation. In the lowest energy snapshot (1631 - 1660 ps), the largest minor groove width is $14.1 \AA$ at the T6/G7 base pair step.

The production dynamics simulation at the G25 site employing DFT charges ran for 9.88 ns. In the lowest energy

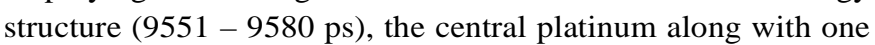
aliphatic linker and terminal Pt group are located in the vicinity of the minor groove while the other aliphatic linker and terminal Pt group points away from the DNA. The next two lowest energy minimised structures are between 491 - 520 ps and 7811 - 7840 ps, respectively. In these structures, the central platinum and one aliphatic linker and corresponding terminal $\left\{\mathrm{PtN}_{4}\right\}$ moiety of the complex are in the vicinity of the minor groove and the other aliphatic linker and terminal $\left\{\mathrm{PtN}_{4}\right\}$ group are extending around the phosphate backbone into the major groove. There are some interesting structures in this simulation where the complex appears folded over and the two terminal Pt groups are in close proximity (3161 - 3190 ps and 8831 - 8860 ps). The conformations have high energy and the complex does not remain in this position for long. The largest minor groove width (15.1 $\AA$ ) is observed at the A5/T6 base pair step of the 1631-1660 ps snapshot. This was accompanied by a narrowed width at the G7/G8 base pair step, two steps away from the widest point. The lowest energy structure (9551 - 9580 ps) had a minor groove width of $13.2 \AA$ and $13.0 \AA$ at the A5/T6 and T9/A10 base pair steps respectively, with a narrowed groove width of $11.1 \AA$ two steps away at G7/G8.

\section{$\left[{ }^{1} \mathrm{H},{ }^{15} \mathrm{~N}\right] \mathrm{NMR}$ experiments. Reaction of 1 with duplex I}

The reaction of $\mathbf{1}$ with $\mathbf{I}$ ( $\mathrm{pH} 5.4,298 \mathrm{~K}$ ) was followed over a period of $46 \mathrm{~h}$ and representative $\left[{ }^{1} \mathrm{H},{ }^{15} \mathrm{~N}\right]$ HSQC NMR spectra are shown in Fig. 5. ${ }^{1} \mathrm{H}$ and ${ }^{15} \mathrm{~N}$ chemical shifts of the species observed during the reaction are listed in Table 1 in comparison to those seen on reaction of $\mathbf{1}$ with the DNA duplexes $5^{\prime}$ d(ATATGTACATAT) $)_{2}$ (II) and 5'-d $\{\text { TATACTAGTATA }\}_{2}$ (III), as well as $1,1 / t, t$ with duplex I. Initially peaks are observed for the dichloro species (1) at $\delta 3.90 /-64.3$ in the Pt$\mathrm{NH}_{3}$ region and $\delta 5.05 /-47.1$ in the $\mathrm{Pt}-\mathrm{NH}_{2}$ region for the terminal $\left\{\mathrm{PtN}_{3} \mathrm{Cl}\right\}$ groups and at $\delta 4.28 /-63.3$ for the $\mathrm{Pt}-\mathrm{NH}_{3}$ groups of the central linker. A small peak at $\delta 4.18 /-62.2$ is observed in the first spectrum recorded after 18 minutes and is assigned to the terminal $\left\{\mathrm{PtN}_{3} \mathrm{O}\right\}$ group of the aquachloro species (2). Its partner peak is assumed to be coincident with the peak for the dichloro species (1).

The ${ }^{1} \mathrm{H} /{ }^{15} \mathrm{~N}$ shifts of the terminal $\mathrm{Pt}-\mathrm{NH}_{3}$ groups $(\delta 3.90 /-$ 64.3) are identical to those seen for $\mathbf{1}$ in the presence of other sequences (e.g. II and III) where the ${ }^{1} \mathrm{H}$ resonances are slightly deshielded $(\delta \Delta=0.04)$ compared to a sample of 1 in the absence of DNA, under identical conditions, consistent with $\mathrm{H}$ bonding interactions between the $\mathrm{Pt}-{ }^{15} \mathrm{NH}_{3}$ groups and the phosphate backbone of the DNA. The cross-peak corresponding to the $\left\{\mathrm{PtN}_{3} \mathrm{O}\right\}$ end of the monoaqua monochloro species, 2 has a similar pronounced downfield shift $\left(\Delta \delta{ }^{1} \mathrm{H}=0.18\right)$ to the previous reactions, consistent with a stronger electrostatic interaction with the duplex than for $\mathbf{1}$, as a consequence of the increased charge $(+2)$. For the reaction with duplex II and III the linker $\mathrm{Pt}-\mathrm{NH}_{3}$ groups of $\mathbf{1}$ were strongly deshielded compared to the control sample $\left(\delta \Delta{ }^{1} \mathrm{H}=0.12 ;{ }^{15} \mathrm{~N}=0.4\right)$ and a similar deshielding effect is seen for the linker $\mathrm{Pt}-\mathrm{NH}_{3}$ groups in the presence of duplex $\mathbf{I}$, consistent with the pre-association in the minor groove.

As the reaction proceeds, peaks assignable to at least two monofunctionally bound species are observed. A peak assigned to the $\left\{\mathrm{PtN}_{3} \mathrm{Cl}\right\}$ group (unbound end) of the combined monofunctional adducts (labelled $\mathbf{3 b} / \mathbf{4 b}$ ) is seen at $\delta 3.92 /-$ 64.5 , adjacent to the peak corresponding to the dichloro starting material (1). The deshielding by $\Delta \delta \square=0.02$ is typically observed (except interestingly in the case of the reaction with the $3^{\prime}-3^{\prime}$ sequence III $)^{8}$ and is indicative of similar $\mathrm{H}$-bonding interactions between the $\mathrm{NH}_{3}$ groups of the unbound $\left\{\mathrm{PtN}_{3} \mathrm{Cl}\right\}$ group and the DNA phosphate backbone. Two peaks appear (each with similar time dependent behaviour as the peak corresponding to $\mathbf{3 b}$ and $\mathbf{4 b}$ ) and are assigned to the $\mathrm{Pt}-\mathrm{NH}_{3}$ groups bound to guanine N7 in two different monofunctional adducts. The peak 3a ( $\delta$ 4.19/-59.7) appears before 4a ( $\delta$ 4.31/-61.1) and they are assigned to the $3^{\prime}$ (G8) and 5' (G7) monofunctional adducts, respectively, based on the similarity of their ${ }^{1} \mathrm{H} /{ }^{15} \mathrm{~N}$ chemical shifts to peaks assigned to these monofunctional adducts in the reaction of $1,1 / t, t$ with $\mathbf{I}$ (see 
Table 1). ${ }^{13}$ In that case assignment was made in part based on identification of the major final adduct (the $1,4 \mathrm{G}(8) \mathrm{G}(18)$ IXL), noting that the enhanced nucleophilicity of GG sites over isolated guanines results in preferential monofunctional platination at G8 and G7 over the G18 or G25 sites. Notably, in the reaction between cisplatin with the same sequence $\mathbf{I}$, an excess of $90 \%$ of platination was found at the GG site with preferential monoadduct formation at the $3^{\prime}$ (G8) site. ${ }^{16}$

Interestingly, the peak 3a, assigned to the $3^{\prime}$ monofunctional species, develops an asymmetry in the early stages of the reaction, indicative of two distinct environments, and no similar asymmetry was observed for the reaction with $1,1 / t, t{ }^{13}$ A reasonable interpretation, based on the results with 2 above, is that the asymmetry arises from the different approach of the terminal $\left\{\mathrm{PtN}_{3} \mathrm{Cl}\right\}$ group to $\mathrm{G} 8 \mathrm{~N} 7$ in the major groove from the two different pre-association sites in the minor groove, so that the monofunctional adducts are aligned in different directions along the DNA.

The chemical environment of the N7 guanine bound end of each monofunctional species is not substantially different to the environment of the bifunctional adduct that is formed from it. For this reason the ${ }^{1} \mathrm{H} /{ }^{15} \mathrm{~N}$ peaks of the $\left\{\mathrm{PtN}_{3} \mathrm{~N}_{7} \mathrm{G}\right\}$ group of the monofunctional (3 or 4) and bifunctional species (5) are overlapped. At the end of the reaction there are two major broadened peaks ( $\delta 4.32 /-60.7$ and $\delta 4.18 /-59.5$ ) assignable to terminal $\mathrm{Pt}-\mathrm{NH}_{3}$ groups in bifunctional adducts. Three peaks observed at $\delta 4.54 /-60.1, \delta 4.49 /-59.6$ and $\delta 4.44 /-59.8$ that account for less than $7 \%$ of the total product profile have been designated as minor products (6) and excluded from the kinetic analysis (see below).

For the reaction of $1,1 / t, t$ with duplex $\mathbf{I}$ the major bifunctional adduct was identified, by analysis of a ${ }^{1} \mathrm{H}$ NOESY NMR spectrum of the final product mixture, as two conformational forms of the $1,4 \mathrm{G}(8) \mathrm{G}(18)$ IXL. The same approach was attempted here but the ${ }^{1} \mathrm{H}$ NOESY NMR spectrum obtained could not be analysed due to the greater complexity of the products formed. Fig. 6 shows the imino region of the ${ }^{1} \mathrm{H}$ NMR spectra of the final products of the reaction of $\mathbf{1}$ and $\mathbf{I}$, in comparison to that obtained from the identical reaction with $1,1 / t, t^{13}$ It is evident that the adduct profile is different for the dinuclear and trinuclear complexes and there are a mixture of products in the latter case.

\section{Kinetic Analysis}

For the purposes of the kinetic fit of the reaction of ${ }^{15} \mathrm{~N}-\mathbf{1}$ with $\mathbf{I}$ the concentration of species present at each time point were obtained from the relative volumes of peaks in the terminal Pt$\mathrm{NH}_{3}$ region, as described previously for the reactions of $1,1 / t, t$ with this sequence. ${ }^{13}$ However in the present case, the ${ }^{1} \mathrm{H},{ }^{15} \mathrm{~N}$ peaks representing the N7G bound end of the monofunctional species (3a, 4a) are coincident with the peaks for the bifunctional adduct (5) and it was not possible to determine the concentration of the individual monofunctional adducts. Their total concentration was derived from the discrete peak $(\mathbf{3 b}, \mathbf{4 b})$ for the unbound $\left\{\mathrm{PtN}_{3} \mathrm{Cl}\right\}$ end. The reaction pathway for the kinetic model used is shown in Scheme 2. The computer best fits for the rate constants are shown in Fig. 7 and the rate constants obtained are listed in Table 2, in comparison with those obtained for the reaction of $1,1 / t, t$ with duplex $\mathbf{I}^{13}$ and $\mathbf{1}$ with $5^{\prime}$-d(ATATGTACATAT) 2 (II), ${ }^{7}$ under similar conditions, and analysed by the same kinetic model.

\section{Discussion}

\section{Influence of pre-association on adduct structure}

In earlier work we provided evidence, based on NMR experiments combined with molecular modelling, that preassociation of $\mathbf{1}$ in the DNA minor groove dictates the nature and structure of the crosslinks formed. ${ }^{7}$ For reaction with duplex II we argued that the central linker group of $\mathbf{1}$ remains in the minor groove on formation of the final 1,4-IXL, and this was subsequently observed for a 1,4-GG IXL formed with an 8mer DNA sequence. ${ }^{11}$ On the other hand for formation of the 1,6-IXL cross-link with the sequence 5'd $\{\text { TATGTATACATA }\}_{2}$, the distance between the two guanine residues is too far if the central linker remains in the initial position in the minor groove and we proposed that $\mathbf{1}$ must "diffuse" off the DNA for covalent binding to occur. ${ }^{7}$ Models of the possible pre-association states of $\mathbf{1}$ with duplexes $\mathbf{I}$ and II were presented where the central $\left\{\mathrm{PtN}_{4}\right\}$ moiety is located in the minor groove, with the aliphatic carbon chains and their associated terminal $\left\{\mathrm{PtN}_{3} \mathrm{Cl}\right\}$ moieties approaching the $\mathrm{N} 7$ of the guanines in the major groove by interleaving the two aliphatic chains between the phosphate groups of the backbone.

The molecular dynamics simulations performed in this study, to examine the interaction of $\mathbf{0}$ with duplex $\mathbf{I}$, showed that the complex spends a significant amount of time within, or close to, the minor groove. Structures where the central platinum is located in the minor groove and the aliphatic linkers extend into the major groove, in opposite directions, often represent the lowest energy structures of the snapshots selected. Indeed a number of snapshots in the molecular dynamics simulations have structures similar those observed in the X-ray crystal structure of $\mathbf{0}$ bound non-covalently to the DickersonDrew Dodecamer, where hydrogen bonding with phosphate oxygens results in either backbone tracking or minor groove spanning through formation of "phosphate clamps". 9 The fact that simulations employing DFT charges for $\mathbf{0}$ adopt structures close to the crystal structure indicates that this method gives a realistic representation of the charge distribution on the trinuclear complex. ${ }^{15}$

In a number of snapshots of the molecular dynamics simulations it was observed that a significant widening of the minor groove at a particular base pair step resulted in a small but significant widening of the adjacent base pair step accompanied by a narrowing of the minor groove at the base pair step two bases away. The structural changes are consistent 
with the specific chemical shift changes observed in the ${ }^{1} \mathrm{H}$ NMR spectrum of duplex $\mathbf{I}$ on addition of $\mathbf{0}$.

Overall the results confirm that pre-association of the central linker of $\mathbf{1}$ within the minor groove will strongly influence the nature of the final adducts formed. While the complexity of the ${ }^{1} \mathrm{H}$ NOESY NMR spectrum precluded characterisation of the final products, it is evident that there are a mixture of adducts, rather than the predominant $5^{\prime}-5^{\prime} 1,4$ G(8)G(18) IXL formed by the dinuclear $1,1 / t, t$ with duplex $\mathbf{I}^{13}$ Given that initial platination occurs at the 3' G8 residue, and there is evidence that there are two conformers of this monofunctional adduct aligned in different directions along the DNA, then the $3^{\prime}-3^{\prime} 1,5 \mathrm{G}(8) \mathrm{G}(25)$ adduct is plausible. While our study of the interaction of 1 with $5^{\prime}-$ d $\{\text { TATACTAGTATA }\}_{2}$ showed that the $3^{\prime}-3^{\prime}$ 1,4-GG IXL, did not form, ${ }^{8}$ the longer 1,5 IXL may yield a less distorted structure than revealed in the molecular dynamics simulations of the $3^{\prime}-3^{\prime}$ 1,4-GG IXL. ${ }^{8}$ For a similar reason the minor monofunctional adduct, from platination at the 5' G8 residue, is most likely to form the $5^{\prime}-5^{\prime} 1,5-G G$ IXL between G7 and G18, rather than the alternative $3^{\prime}-3^{\prime} 1,4-G(7) G(25)$ IXL.

\section{Kinetics of crosslink formation}

As observed previously for reactions of $\mathbf{1}$ with different DNA duplexes $^{7}$ pre-association has a strong influence on the aquation step, as can be seen from a comparison of the value of the pseudo-first-order rate constants with those of the forward (aquation) rate constant for $\mathbf{1}$ under the same conditions of $\mathrm{pH}$ and ionic strength in the absence of DNA (Table 2). In the presence of duplex $\mathbf{I I}^{7}$ the value of $k_{\mathrm{H}}$ is 2.7 fold lower, and an even greater (3-fold) lowering is observed in the presence of duplex I. This effect is attributed to pre-association restricting access of the solvent to the $\mathrm{Pt}$ coordination sphere and hindering formation of the five-membered transition state necessary for substitution (aquation) reactions. ${ }^{7}$ The rate constant for combined monofunctional adduct formation is $c a$. 2-fold higher for 1,1/t,t compared to 1 . A possible explanation is that for $\mathbf{1}$ the strong pre-association in the minor groove alters the approach to the N7 of guanine in the major groove. A similar lowering of the rate constant for monofunctional binding was observed for ${ }^{15} \mathrm{~N}-1$ binding to $5^{\prime}$ d(ATATGTACATAT) 2 (II) in comparison to $1,1 / t, t .{ }^{7}, 17$ The rate constant for monofunctional binding is 2.4 fold greater for $\mathbf{1}$ binding to duplex $\mathbf{I}$ than to the isolated $\mathrm{G}$ in duplex $\mathbf{I I}^{7}$, and a similar effect was observed for the binding of $1,1 / t, t$ to $\mathbf{I}$ and II, ${ }^{13}, 17$ consistent with the enhanced nucleophilicity of the GG site. Surprisingly, the rate constant for conversion of the combined monofunctional species to the combined bifunctional adducts is two fold higher than that observed for the reaction of $1,1 / t, t$ with duplex $\mathbf{I}$, when analysed by the same kinetic model. ${ }^{13}$ In most other kinetic studies of interstrand crosslinking by multinuclear platinum complexes performed to date, ${ }^{7,13,} 18$ similar rate constants have been observed for the aquation step and for bifunctional adduct formation, consistent with aquation of the monofunctional adduct occuring prior to fixation of the cross-link and this step being rate limiting. A possible explanation for the higher value of $k_{\mathrm{BF}}$ is that, at least for some environments of the combined monofunctional adducts, the $\left\{\mathrm{PtN}_{3} \mathrm{Cl}\right\}$ end group is pointing away from the DNA so that restricted access of the solvent to the $\mathrm{Pt}$ coordination sphere is less significant than in the preassociated states.

\section{Experimental}

\section{Chemicals}

The sodium salts of the HPLC purified oligonucleotides $5^{\prime}$ d(ATACATGGTACATA) (Ia) and 5' d(TATGTACCATGTAT) (Ib) were purchased from either OSWEL or Proligo. The nitrate salts of the fully ${ }^{15} \mathrm{~N}$ labelled $\left[\text { trans-PtCl }\left({ }^{15} \mathrm{NH}_{3}\right)_{2}\right\}_{2}$ ( $\mu$-trans-Pt $\left({ }^{15} \mathrm{NH}_{3}\right)_{2}\left({ }^{15} \mathrm{NH}_{2}\left(\mathrm{CH}_{2}\right)_{6}-\right.$ $\left.\left.\left.{ }^{15} \mathrm{NH}_{2}\right)_{2}\right\}\right]^{4+}\left({ }^{15} \mathrm{~N}-1\right)$ and non-labeled $\left[\left\{\text { trans-Pt }\left(\mathrm{NH}_{3}\right)_{3}\right\}_{2}(\mu-\right.$ trans-Pt $\left.\left.\left(\mathrm{NH}_{3}\right)_{2}\left(\mathrm{NH}_{2}\left(\mathrm{CH}_{2}\right)_{6} \mathrm{NH}_{2}\right)_{2}\right\}\right]^{6+} \quad$ (0) were prepared according to the previously reported procedures. ${ }^{19,} 20$

\section{NMR spectroscopy}

NMR spectra involving ${ }^{15} \mathrm{~N}-1$ were recorded on a Varian UNITY-INOVA-600 spectrometer $\left({ }^{1} \mathrm{H}, 599.924 \mathrm{MHz},{ }^{15} \mathrm{~N}\right.$, $60.79 \mathrm{MHz}$ ). Both the $1 \mathrm{D}{ }^{15} \mathrm{~N}$ - edited ${ }^{1} \mathrm{H} \mathrm{NMR}$ spectra and $2 \mathrm{D}$ $\left[{ }^{1} \mathrm{H},{ }^{15} \mathrm{~N}\right]$ HSQC NMR spectra (optimized for ${ }^{1} J\left({ }^{15} \mathrm{~N},{ }^{1} \mathrm{H}\right)=72$ $\mathrm{Hz}$ ) were recorded using the sequence of Stonehouse et al. ${ }^{21}$ For kinetics studies involving $\left[{ }^{1} \mathrm{H},{ }^{15} \mathrm{~N}\right]$ HSQC NMR spectra, between 4 and 12 transients were collected for $16-64$ increments of $t_{1}$ (allowing spectra to be recorded on a suitable timescale for the observed reaction), with an acquisition time of 0.152 seconds, spectral widths of $4 \mathrm{kHz}$ in $t_{2}\left({ }^{1} \mathrm{H}\right)$ and 1.823 $\mathrm{kHz}$ in $t_{1}\left({ }^{15} \mathrm{~N}\right)$. 2D spectra were completed in $14-30$ minutes. The 2D HSQC spectra were processed using Gaussian weighting functions in both dimensions, and zero-filling by $\times 2$ in the $f_{1}$ dimension. The ${ }^{15} \mathrm{~N}$ signals were decoupled by irradiating with the GARP-1 sequence at a field strength of 1 $\mathrm{kHz}$ during the acquisition time.

NMR spectra involving $\mathbf{0}$ were recorded on a Bruker Avance $600 \mathrm{MHz}$ spectrometer $\left({ }^{1} \mathrm{H}, 600.13 \mathrm{MHz}\right)$. The ${ }^{1} \mathrm{H}$ NMR spectra were recorded using a $5 \mathrm{~mm}$ triple resonance probehead equipped with pulsed field gradients and were acquired with water suppression using the WATERGATE sequence. $^{22}$ The NOESY spectra were recorded using the WATERGATE NOESY pulse sequences. ${ }^{22,23}$ Typically for 1D ${ }^{1} \mathrm{H}$ spectra, 64 or 128 transients were acquired using a spectral width of $12 \mathrm{kHz}$, a relaxation delay of 1.5 seconds, and a line broadening of $1.0 \mathrm{~Hz}$. For the NOESY experiments, 16 transients were acquired in the $f_{2}$ dimension with a spectral width of $12 \mathrm{KHz}$ into 4096 data points for each of the $1024 t_{1}$ increments and a relaxation delay of $2.5 \mathrm{~s}$. The mixing time of these experiments was $200 \mathrm{~ms}$. The NOESY spectra were processed using the QSINE function in both dimensions. SI values of 2048 were used in both the $f_{1}$ and $f_{2}$ dimensions, 
which amounted to zero filling of 1024 points in the $f_{1}$ dimension.

All samples (including buffers, acids, etc.) were prepared so that there was a $5 \% \mathrm{D}_{2} \mathrm{O}$ concentration in $\mathrm{H}_{2} \mathrm{O}$ (for deuterium lock but with minimal loss of signal as a result of deuterium exchange). Spectra were recorded at $298 \mathrm{~K}$, and the sample was maintained at this temperature when not immersed in the NMR probe. ${ }^{1} \mathrm{H}$ chemical shifts were referenced to TSP (sodium 3-trimethylsilyl-[D4]-propionate) and ${ }^{15} \mathrm{~N}$ chemical shifts were calibrated externally against ${ }^{15} \mathrm{NH}_{4} \mathrm{Cl}(1.0 \mathrm{M}$ in 1.0 $\mathrm{M} \mathrm{HCl}$ in $5 \% \mathrm{D}_{2} \mathrm{O}$ in $\mathrm{H}_{2} \mathrm{O}$ ).

\section{pH measurements}

The $\mathrm{pH}$ of the solutions was measured on a Shindengen $\mathrm{pH}$ Boy-P2 (su19A) pH meter and calibrated against $\mathrm{pH}$ buffers at pH 6.9 and 4.0. A volume of $5 \mu \mathrm{L}$ of the solution was placed on the electrode surface and the $\mathrm{pH}$ recorded. These aliquots were not returned to the bulk solution in order to eliminate the leaching of $\mathrm{Cl}^{-}$. Adjustments in $\mathrm{pH}$ were made using $0.04 \mathrm{M}$, $0.2 \mathrm{M}$, and $1.0 \mathrm{M} \mathrm{HClO}_{4}$ (or $1.0 \mathrm{mM} \mathrm{HNO}_{3}$ ) in $5 \% \mathrm{D}_{2} \mathrm{O}$ in $\mathrm{H}_{2} \mathrm{O}$, or $0.04 \mathrm{M}, 0.2 \mathrm{M}$, and $1.0 \mathrm{M} \mathrm{NaOH}$ in $5 \% \mathrm{D}_{2} \mathrm{O}$ in $\mathrm{H}_{2} \mathrm{O}$.

\section{Preparation of DNA duplex I}

For the reactions of ${ }^{15} \mathrm{~N}-\mathbf{1}$ with duplex I stock solutions of Ia and Ib were prepared in $500 \mu \mathrm{L} 5 \% \mathrm{D}_{2} \mathrm{O}$ in $\mathrm{H}_{2} \mathrm{O}$. The concentrations were estimated spectrophotometrically to be $12.53 \mathrm{mM}$ and $15.41 \mathrm{mM}$, respectively, using the absorption coefficient calculated using the method described by Kallansrud and Ward $\left(\varepsilon_{260}=110.3 \times 10^{3} \mathrm{M}^{-1} \mathrm{~cm}^{-1}\right.$ and $101.4 \times$ $10^{3} \mathrm{M}^{-1} \mathrm{~cm}^{-1}$ for Ia and Ib, respectively). ${ }^{24}$

For the reaction of $\mathbf{0}$ with duplex $\mathbf{I}$, the single strands, Ia and $\mathbf{I b}$, were purified using NAP-25 columns (Pharmacia). The resulting solutions were dialysed against $0.5 \mathrm{mM} \mathrm{Na} \mathrm{NO}_{4}$ buffer, and then freeze-dried. Subsequently, aliquots of Millipore water was added to Ia $(150 \mu \mathrm{L})$ and Ib $(175 \mu \mathrm{L})$ resulting in stock solutions of $4.8 \mathrm{mM}$ and $2.8 \mathrm{mM}$, respectively (calculated as described above).

\section{Platination of duplex I with ${ }^{15} \mathrm{~N}-1$}

Duplicate reactions were prepared in the following manner. $63.8 \mu \mathrm{l}$ of stock solution of Ia $(12.53 \mathrm{mM})$ and $53.9 \mu \mathrm{L}$ of $\mathbf{I b}$ (15.41 mM) were combined with $30 \mu \mathrm{L} \mathrm{Na} \mathrm{PO}_{4}$ buffer (200 $\mathrm{mM}, \mathrm{pH} 5.3$ ) and $2 \mu \mathrm{L}$ of TSP solution (13.3 mM) in $230.3 \mu \mathrm{L}$ of $5 \% \mathrm{D}_{2} \mathrm{O}$ in $\mathrm{H}_{2} \mathrm{O}$. The samples were heated in a hot water bath $\left(60-70^{\circ} \mathrm{C}\right)$ and subsequently allowed to cool to room temperature. A $20 \mu \mathrm{L}$ aliquot of a freshly prepared solution of ${ }^{15} \mathrm{~N}-1$ (1.12 mg, $\left.0.90 \mu \mathrm{mol}\right)$ in $28.0 \mu \mathrm{L}$ of $5 \% \mathrm{D}_{2} \mathrm{O}$ in $\mathrm{H}_{2} \mathrm{O}$ was added to the duplex resulting in a total volume of $400 \mu \mathrm{L}$, and a concentration of duplex I (2.0 mM), $\mathrm{Na}_{3} \mathrm{PO}_{4}(15 \mathrm{mM})$ and ${ }^{15} \mathrm{~N}-$ 1 (1.6 mM), respectively. The reaction was followed at $298 \mathrm{~K}$ by ${ }^{1} \mathrm{H}$ and $\left[{ }^{1} \mathrm{H},{ }^{15} \mathrm{~N}\right] \mathrm{NMR}$ over a time period of 46 hours. The final $\mathrm{pH}$ of the solution was found to be 6.2. No precipitate was observed during the reaction of ${ }^{15} \mathrm{~N}-\mathbf{1}$ with the oligonucleotide. Kinetic runs were carried out at $298 \mathrm{~K}$, and covered the time periods $0-46$ hours and $0-19$ hours, to maximize the use of NMR time. Samples were maintained at $298 \mathrm{~K}$ when not in the spectrometer. Kinetic data were derived from both experiments in which spectra with identical reaction times were collected to confirm that the rates of reaction were identical.

\section{Reaction of duplex I with 0}

Into a $5 \mathrm{~mm}$ Shigemi tube were combined stock solutions of 1a (69.4 $\mu \mathrm{L}$ of $4.8 \mathrm{mM}$ solution) and Ib $(132.9 \mu \mathrm{L}$ of $2.8 \mathrm{mM}$ solution), $\mathrm{D}_{2} \mathrm{O}(17.5 \mu \mathrm{L})$ TSP $(2 \mu \mathrm{L}, 13.3 \mathrm{mM}), \mathrm{Na}_{3} \mathrm{PO}_{4}(128$ $\mu \mathrm{L}, 55 \mathrm{mM}, \mathrm{pH}$ 5.25) and $\mathrm{NaCl}(5 \mu \mathrm{L}, 3.47 \mathrm{M})$. The concentration of the final solution of duplex $\mathbf{I}$ was estimated to be $0.93 \mathrm{mM}$ with a $\mathrm{pH}$ of 5.4 and a volume of $355 \mu \mathrm{L}$, in 20 $\mathrm{mM} \mathrm{Na}_{3} \mathrm{PO}_{4}$ and $50 \mathrm{mM} \mathrm{NaCl}$. The sample was heated in a hot water bath $\left(60-70^{\circ} \mathrm{C}\right)$ and subsequently allowed to cool to room temperature. In order to examine the possibility of two association sites, a $20 \mu \mathrm{L}$ aliquot of a solution of $\mathbf{0}$ (35.2 mM in $\mathrm{H}_{2} \mathrm{O}$ ) was added to the solution of duplex I, resulting in a $\mathbf{0}$ :I ratio of approximately 2:1. NOESY spectra were then recorded at $298 \mathrm{~K}$.

\section{Data Analysis}

Kinetic analysis. An analysis of the kinetic profile of the reaction between ${ }^{15} \mathrm{~N}-1$ and duplex $\mathbf{I}$ was accomplished by measuring the peak volumes from the $\mathrm{NH}_{3}$ region of the $\left[{ }^{1} \mathrm{H},{ }^{15} \mathrm{~N}\right]$ HSQC NMR spectra as previously described. ${ }^{7,} 13$ The VNMR software package was used to integrate the peaks and provide the volumes over the course of the experiment. All species depicted in Scheme 1, other than ${ }^{15} \mathrm{~N}$-1, gave rise to two $\mathrm{NH}_{3}$ peaks for the non-equivalent $\left\{\mathrm{PtN}_{3} \mathrm{Y}\right\}$ groups. In some cases, overlap between peaks was significant (as with the peak for the non-aquated $\left\{\mathrm{PtN}_{3} \mathrm{Cl}\right\}$ group of the aquachloro species (2), which is coincident with the peak for the dichloro species $(\mathbf{1}))^{25}$, but in these instances, it was only one of the pair of the peaks that was overlapped. Thus, reliable intensities were obtained by doubling the volume of the second (discrete) peak. Comparison of the time dependent changes of the observed peaks in the $\mathrm{Pt}-\mathrm{NH}_{2}$ region of the $\left[{ }^{1} \mathrm{H},{ }^{15} \mathrm{~N}\right]$ HSQC NMR spectra was used to confirm the peak assignments.

The appropriate differential equations were integrated numerically, and rate constants determined by a nonlinear optimization procedure using the program SCIENTIST (Version 2.0, MicroMath, Inc.). The errors represent one standard deviation. In all cases the data were fit using appropriate first and second-order rate equations. The SCIENTIST input files are available in Supporting Information.

NOESY assignment strategy. Assignment of NOE connectivities observed between $\mathbf{0}$ and duplex $\mathbf{I}$ was based on that employed by Qu et al. ${ }^{11}$ in which the carbon atoms on the aliphatic linker of $\mathbf{0}$ were numbered 1 through 6 and 1' through $6^{\prime}$ for each of the two $\left(\mathrm{CH}_{2}\right)_{6}$ chains (Fig. 3). The assignment 
procedure was as follows: After assignment of the NOESY spectra of the 0:I mixture, the regions of various $\mathrm{CH}_{2}$ and $\mathrm{NH}_{3}$ protons were identified based on previous assignments. ${ }^{11}$ The NOESY cross peaks at ca. $\delta 1.38$ in the $f_{1}$ dimension can be assigned as either the 3,4 or $3^{\prime}, 4^{\prime} \mathrm{CH}_{2}$ groups. Once this arbitrary determination is made the complex is anchored and further assignment possible based on connectivity to the adenine $\mathrm{H} 2$ protons. The peaks around $\delta 1.64$ and $\delta 2.65$ in the $f_{1}$ dimension represent $2,5 / 2^{\prime}, 5^{\prime}$ and $1,6 / 1^{\prime}, 6^{\prime}$, respectively, depending on the closest DNA proton based on the initial assignment. For the $\mathrm{NH}_{3}$ region between $\delta 4.00-4.35$, the protons were labelled as shown in Fig. 3 for the two molecules labelled $\mathrm{x}$ and $\mathrm{y}$, which correspond to the G25 and G18 preassociation sites, respectively.

\section{Molecular Modelling}

DFT calculations were performed using the ADF 2002 package $^{26}$ on the supercomputer at the Australian Partnership of Advanced Computing (APAC) National Facility located in Canberra, Australian Capital Territory. Non-relativistic calculations using $\mathrm{ZORA}^{27}$ basis sets were performed on $\mathbf{0}$. The Triple- $\zeta$ polarised ZORA basis set was used for the platinum atom with a frozen core approximation applied up to the 4d energy level. For nitrogen, chlorine and carbon, the double- $\zeta$ polarised ZORA basis set was used whereas the double- $\zeta$ ZORA basis set was used for hydrogen. Geometry optimisations were performed using the $\mathrm{VWN}^{28}$ form of the local density approximation (LDA). Although these calculations were non-relativistic, the use of ZORA basis sets allowed for some incorporation of relativistic effects.

Molecular dynamics were performed on $\mathbf{0}$ with I using the AMBER 7 molecular dynamics package. ${ }^{29}$ The Pt complex was placed approximately $20 \AA$ from relaxed DNA with counter ions solvated with water. A series of dynamics and mechanics were performed with gradually decreasing restraints on the DNA, followed by 200 ps of unrestrained dynamics. The system was deemed equilibrated by visual inspection of several parameters including total energy of the system. Once the system had been equilibrated, $\mathbf{0}$ was docked close to I. Based on NOE connectivities, which suggest that two molecules of $\mathbf{0}$ bind to I, the two pre-association sites (G25 and G15) were examined. Following the docking, approximately 10 ns of production dynamics were performed in each case. The simulations were viewed using the $\mathrm{VMD}^{30}$ suite of programs and structures representing periods of interest in the simulation were selected and minimised, with the resulting structures input into $\mathrm{X} \mathrm{DNA}^{31}$ and structural characteristics determined. Pictures were rendered using POV-ray v3.11g. ${ }^{32}$

\section{Conclusions}

Overall the results confirm that pre-association of the central linker of $\mathbf{1}$ within the minor groove will strongly influence the nature of the final adducts formed. Under physiological conditions the G(N7)-Pt bonds in site-specific DNA-BBR3464 cross-links are labile. ${ }^{33}$ The multiple DNA cross-links upon covalent bond formation of BBR3464 observed here confirms the view that these crosslinks may all contribute substantially to the cytotoxicity of the drug, which may be beneficial with respect to development of specific DNA repair mechanisms and development of resistance. ${ }^{33}$ The DNA binding motif of the phosphate clamp "in solution" is characterized by high binding affinity, some minor-groove selectivity and highly efficient condensation of DNA. ${ }^{34}$ The dynamics study of the substitution-inert AH44 is of further relevance because the clear residence in the minor groove supports the view from parallel biophysical experiments that the DNA condensation effects are driven by minor-groove affinity. ${ }^{35}$ The simulations, coupled with NMR evidence, ${ }^{12}$ further confirm that the crystallographically observed structures exist in solution and are relevant in explaining the biological activity of this series.

\section{Acknowledgements}

This work was supported by the Australian Research Council (to S.J.B-P and NF) and National Institutes of Health (RO1CA78754), National Science Foundation (INT-9805552 and CHE-9615727) and the American Cancer Society (RPG89-00211-CDD). We thank Dr. Lindsay Byrne for assistance with NMR experiments and the Australian Partnership for Advanced Computing (APAC) for access to the supercomputers.

\section{Notes and references}

${ }^{a}$ School of Chemistry and Biochemistry, University of Western Australia, Crawley, WA 6009, Australia.

${ }^{b}$ Institute for Glycomics, Griffith University, Gold Coast, Queensland 4222, Australia.Email: s.berners-price@griffith.edu.au.

c Department of Chemistry, Virginia Commonwealth University, 1001 W. Main St. , Richmond, Virginia, 23284-2006, USA. Email: npfarrell@vcu.edu I These authors contributed equally to the manuscript

† Present address, Mark Wainwright Analytical Centre, University of New South Wales, Sydney, NSW 2052, Australia.

$¥$ Present address, College of Science, Technology and Engineering, James Cook University, Townsville QLD 4811, Australia.

$\dagger$ Electronic Supplementary Information (ESI) available: [sequential NOESY assignment walks for duplex I; ${ }^{1} \mathrm{H}$ NMR chemical shift changes of duplex I on addition of $\mathbf{0}$ (2:1 ratio); Energies of minimised structures from the production dynamics simulation of $\mathbf{0}$ (non-relativistic DFT Hirshfeld charges) docked at the G18 and G25 sites of duplex I; Scientist equation file used in the fitting of the kinetic plot for reaction of ${ }^{15} \mathrm{~N}-1$ with duplex I]. See DOI: 10.1039/b000000x/

1 L. H. Hurley, Nat. Rev. Cancer, 2002, 2, 188-200; D. R. Boer, A. Canals and M. Coll, J. Chem. Soc. Dalton Trans., 2009, 399-414.

2 J. B. Mangrum and N. P. Farrell, Chem. Comm., 2010, 46, 66406650.

3 N. P. Farrell, Drugs of the Future., 2012, 37, 795-806.

4 J. Kasparkova, J. Zehnulova, N. Farrell and V. Brabec, J. Biol. Chem., 2002, 277, 48076-48086.

5 S. R. Rajski and R. M. Williams, Chem. Rev., 1998, 98, 2723-2796; D. M. Noll, T. M. Mason and P. S. Miller, Chem. Rev., 2006, 106, 277-301. 
6 J. Malina, N. P. Farrell and V. Brabec, Chem. Asian. J., 2011, 6, 1566-1574.

7 A. Hegmans, S. J. Berners-Price, M. S. Davies, D. S. Thomas, A. S. Humphreys and N. Farrell, J. Am. Chem. Soc., 2004, 126, 2166-2180.

8 R. A. Ruhayel, J. J. Moniodis, X. Yang, J. Kasparkova, V. Brabec, S. J. Berners-Price and N. P. Farrell, Chem.-Eur. J., 2009, 15, 93659374.

9 S. Komeda, T. Moulaei, M. Chikuma, A. Odani, R. Kipping, N. P. Farrell and L. D. Williams, Nuc. Acids Res., 2011, 39, 325-336.

10 S. Komeda, T. Moulaei, K. K. Woods, M. Chikuma, N. P. Farrell and L. D. Williams, J. Am. Chem. Soc., 2006, 128, 16092-16103.

11 Y. Qu, N. J. Scarsdale, M.-C. Tran and N. P. Farrell, J. Biol. Inorg. Chem., 2003, 8, 19-28.

12 Y. Qu, J. J. Moniodis, A. L. Harris, X. Yang, A. Hegmans, L. F. Povirk, S. J. Berners-Price and N. P. Farrell, in Polyamine Drug Discovery, ed. P. M. Woster, Royal Society of Chemistry, Cambridge, 2012, pp. 191-204.

13 S. J. Berners-Price, M. S. Davies, J. W. Cox, D. S. Thomas and N. Farrell, Chem.-Eur. J., 2003, 9, 713-725.

14 R. A. Ruhayel, S. J. Berners-Price and N. P. Farrell, Dalton Trans., 2013, 42, 3181 - 3187.

15 J. J. Moniodis, PhD, University of Western Australia, 2006.

16 S. J. Berners-Price, K. J. Barnham, U. Frey and P. J. Sadler, Chem. Eur. J., 1996, 2, 1283-1291; J. A. Parkinson, Y. Chen, Z. Guo, S. J. Berners-Price, T. Brown and P. J. Sadler, Chem. Eur. J., 2000, 6, 3636-3644.

17 J. W. Cox, S. J. Berners-Price, M. S. Davies, Y. Qu and N. Farrell, J. Am. Chem. Soc., 2001, 123, 1316-1326.

18 R. A. Ruhayel, J. S. Langner, M.-J. Oke, I. Zgani, S. J. Berners-Price and N. P. Farrell, J. Am. Chem. Soc., 2012, 134, 7135-7146.

19 M. S. Davies, D. S. Thomas, A. Hegmans, S. J. Berners-Price and N. Farrell, Inorg. Chem., 2002, 41, 1101-1109.

20 Y. Qu, A. Harris, A. Hegmans, A. Petz, P. Kabolizadeh, H. Penazova and N. Farrell, J. Inorg. Biochem., 2004, 98, 1591-1598.

21 J. Stonehouse, G. L. Shaw and J. Keeler, J. Biomol. NMR, 1994, 4, 799-805.

22 M. Piotto, V. Saudek and V. Sklenar, J. Biomol. NMR, 1992, 2, 661666.

23 V. Sklenar, M. Piotto, R. Leppik and V. Saudek, J. Mag. Res. Ser. A, 1993, 102, 241-245.

24 G. Kallansrud and B. Ward, Anal. Biochem., 1996, 236, 134-138.

25 M. S. Davies, J. W. Cox, S. J. Berners-Price, W. Barklage, Y. Qu and N. Farrell, Inorg. Chem., 2000, 39, 1710-1715.

26 G. Te Velde, F. M. Bickelhaupt, E. J. Baerends, C. Fonseca Guerra, S. J. A. Van Gisbergen, J. G. Snijders and T. Ziegler, J. Comp. Chem., 2001, 22, 931-967; Amsterdam Density Functional - Users Manual, Science, Computing and Modelling, Amsterdam, 2005.

27 E. van Lenthe, J. G. Snijders and E. J. Baerends, J. Chem. Phys., 1996, 105, 6505-6516; E. van Lenthe, A. Ehlers and E.-J. Baerends, J. Chem. Phys., 1999, 110, 8943-8953.

28 S. H. Vosko, L. Wilk and M. Nusair, Can. J. Phys., 1980, 58, 12001211.

29 D. A. Pearlman, D. A. Case, J. W. Caldwell, W. S. Ross, T. E. Cheatham, III, S. DeBolt, D. Ferguson, G. Seibel and P. Kollman, Comp. Phys. Commun., 1995, 91, 1-42.
30 W. Humphrey, A. Dalke and K. Schulten, J. Mol. Graph., 1996, 14, 33-38.

31 X.-J. Lu, Z. Shakked and W. K. Olson, J. Mol. Biol., 2000, 300, 819840.

32 C. Cason, POV-Ray(tm) rendering engine for Windows, 3.1g edn., 1999.

33 J. Malina, J. Kasparkova, N. P. Farrell and V. Brabec, Nuc. Acids Res., 2011, 39, 720-728.

34 J. Malina, N. P. Farrell and V. Brabec, Inorg. Chem., 2014, 53, 16621671; J. Malina, N. P. Farrell and V. Brabec, Angew. Chem., 2014, In Press. DOI: 10.1002/anie.201408012R201408011.

35 A. Priseracu, Z. Molphy, R. G. Kipping, E. J. Peterson, A. Kellett and N. P. Farrell, Nuc. Acids Res., Submitted. 


\section{ARTICLE}

Table $1{ }^{1} \mathrm{H} /{ }^{15} \mathrm{~N}$ chemical shifts for the Pt- ${ }^{15} \mathrm{NH}_{3}$ groups of ${ }^{15} \mathrm{~N}-\mathbf{1}$ and the intermediate species observed during the reaction with duplex I (at 298K, pH 5.4). ${ }^{a}$ Data for the reaction of $\mathbf{1}$ with duplexes II and III under similar conditions are shown for comparison, together with those of $1,1 / t, t$ with duplex $\mathbf{I}$.

\begin{tabular}{|c|c|c|c|c|}
\hline species & duplex I & duplex $\mathbf{I I}^{b}$ & duplex III $^{c}$ & 1,1/t,t -duplex $\mathbf{I}^{d}$ \\
\hline \multicolumn{5}{|c|}{ Pt- ${ }^{15} \mathrm{NH}_{3}$ (terminal groups) } \\
\hline $\mathrm{L} / \mathrm{L}^{\prime}$ & $\delta^{1} \mathrm{H} /{ }^{15} \mathrm{~N}$ & $\delta^{1} \mathrm{H} /{ }^{15} \mathrm{~N}$ & $\delta^{1} \mathrm{H} /{ }^{15} \mathrm{~N}$ & $\delta^{1} \mathrm{H} /{ }^{15} \mathrm{~N}$ \\
\hline $\mathrm{Cl} / \mathrm{Cl}$ & $3.90 /-64.3$ & $\begin{array}{c}3.91 /-64.2 \\
(3.86 /-64.4)^{e}\end{array}$ & $3.91 /-64.1$ & $\begin{array}{c}3.90 /-64.2 \\
(3.86 /-64.6)^{e}\end{array}$ \\
\hline$\underline{\mathrm{Cl}} / \mathrm{H}_{2} \mathrm{O}$ & f & $f$ & f & $f$ \\
\hline $\mathrm{Cl} / \underline{\mathrm{H}}_{2} \underline{\mathrm{O}}$ & $4.18 /-62.2$ & $\begin{array}{c}4.19 /-61.8 \\
(4.00 /-62.5)^{c}\end{array}$ & $4.21 /-61.9$ & $\begin{array}{c}4.21 /-62.0 \\
(4.00 /-62.6)\end{array}$ \\
\hline$\underline{\mathrm{Cl}} / \mathrm{GN}_{7}$ & $3.92 /-64.5$ & $3.93 /-64.2$ & $f$ & $3.95 /-64.4$ \\
\hline $\mathrm{Cl} / \underline{G N}_{7}$ & $\begin{array}{c}4.19 /-59.7 \text { (G8) } \\
4.31 /-61.1(\mathrm{G} 7)\end{array}$ & $4.29 /-60.6$ & $g$ & $\begin{array}{l}4.17 /-59.9 \text { (G8) } \\
4.30 /-61.0 \text { (G7) }\end{array}$ \\
\hline
\end{tabular}

${ }^{a}{ }^{1} \mathrm{H}$ referenced to TSP (internal) and ${ }^{15} \mathrm{~N}$ referenced to ${ }^{15} \mathrm{NH}_{4} \mathrm{Cl}$ (external). $\delta$ in ${ }^{15} \mathrm{~N}$ dimension $\pm 0.2 \mathrm{ppm} .{ }^{b}$ Duplex II $=5^{\prime}$ -

$\mathrm{d}(\text { ATATGTACATAT) })_{2}$; from reference ${ }^{7} .{ }^{c}$ Duplex III $=5^{\prime}-\mathrm{d}\{\text { TATACTAGTATA }\}_{2} ;$ from reference ${ }^{8} \cdot{ }^{d}$ From reference ${ }^{13} \cdot{ }^{e}$ The ${ }^{1} \mathrm{H} /{ }^{15} \mathrm{~N}$ chemical shifts in the absence of DNA at $\mathrm{pH} 5.4$. ${ }^{f}$ Assumed to be concealed underneath the cross-peak corresponding to the $\mathrm{Cl} / \mathrm{Cl}$ species. ${ }^{g}$ several cross-peaks assignable to monofunctional adducts (possibly bound to A and G N7) including one peak at $\delta 4.30 /-60.7$.

Table 2. Rate constants for the reactions of 1 with duplex I (at $298 \mathrm{~K}, \mathrm{pH} 5.4)^{a}$

\begin{tabular}{cccc}
\hline Rate constant & $\mathbf{1}$ & $1,1 / t, t t^{b}$ & $\mathbf{1}$ \\
\hline \multicolumn{3}{c}{ duplex I } & duplex II ${ }^{c}$ \\
\hline$k_{\mathrm{H}}\left(10^{-5} \mathrm{~s}^{-1}\right)^{d}$ & $3.43 \pm 0.03$ & $4.00 \pm 0.03$ & $3.94 \pm 0.03$ \\
& $(10.7 \pm 0.1)$ & & $(10.7 \pm 0.1)$ \\
& & & \\
$k_{\mathrm{MF}}\left(\mathrm{M}^{-1} \mathrm{~s}^{-1}\right)$ & $0.6 \pm 0.1$ & $1.5 \pm 0.5$ & $0.25 \pm 0.02$ \\
$k_{\mathrm{BF}}\left(10^{-5} \mathrm{~s}^{-1}\right)$ & $8.0 \pm 0.2$ & $4.20 \pm 0.04$ & $4.21 \pm 0.06$ \\
\hline
\end{tabular}

${ }^{a}$ The rate constants are defined in Scheme $2 .{ }^{b}$ From reference ${ }^{13}$. ${ }^{c}$ Duplex II $=5^{\prime}$ -

d(ATATGTACATAT) ${ }_{2}$; from reference ${ }^{7}$. ${ }^{d}$ Data shown in parentheses are rate constants for the aquation step in the absence of DNA under identical ionic strength and $\mathrm{pH}$, from reference ${ }^{19}$. 

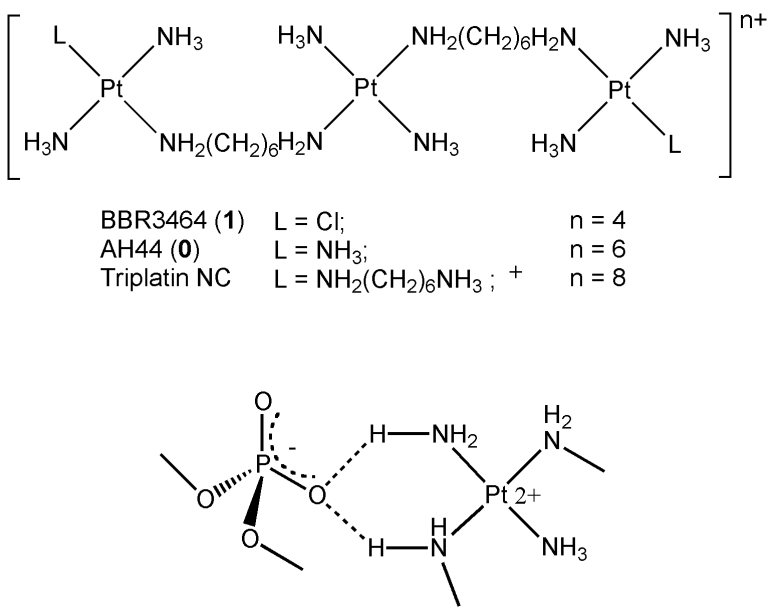

Chart 1 Structures of polynuclear platinum complexes and illustration of a "phosphate clamp"

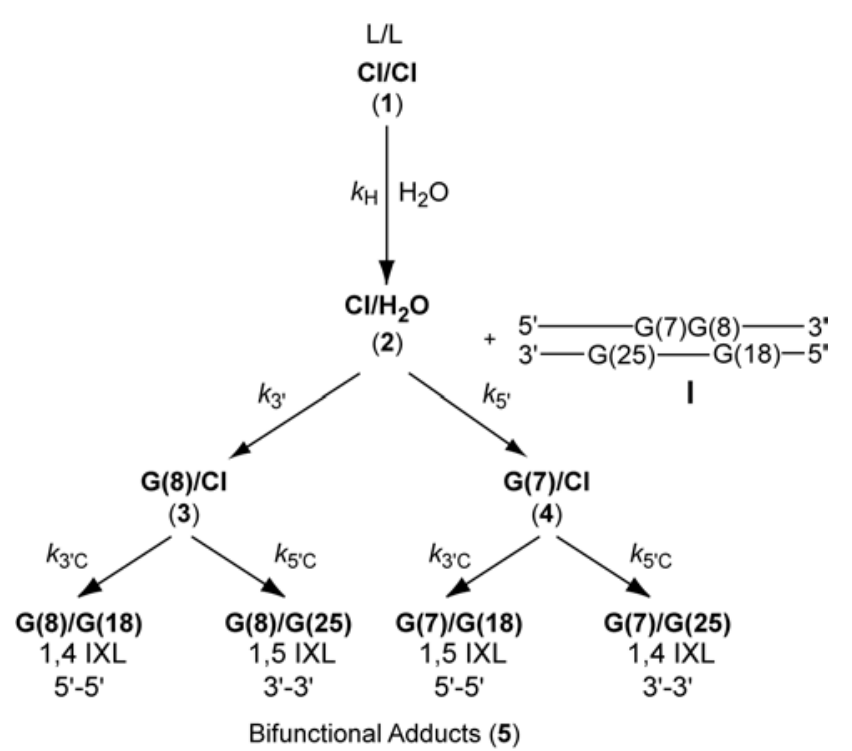

Scheme 1 Reaction pathway depicting the possible adducts formed from the reaction of $\mathbf{1}$ with duplex $\mathbf{I}$

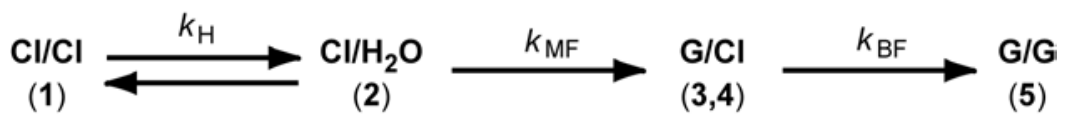

Scheme 2 Kinetic model used to model the rate constants for the reaction of $\mathbf{1}$ with duplex $\mathbf{I}$ 


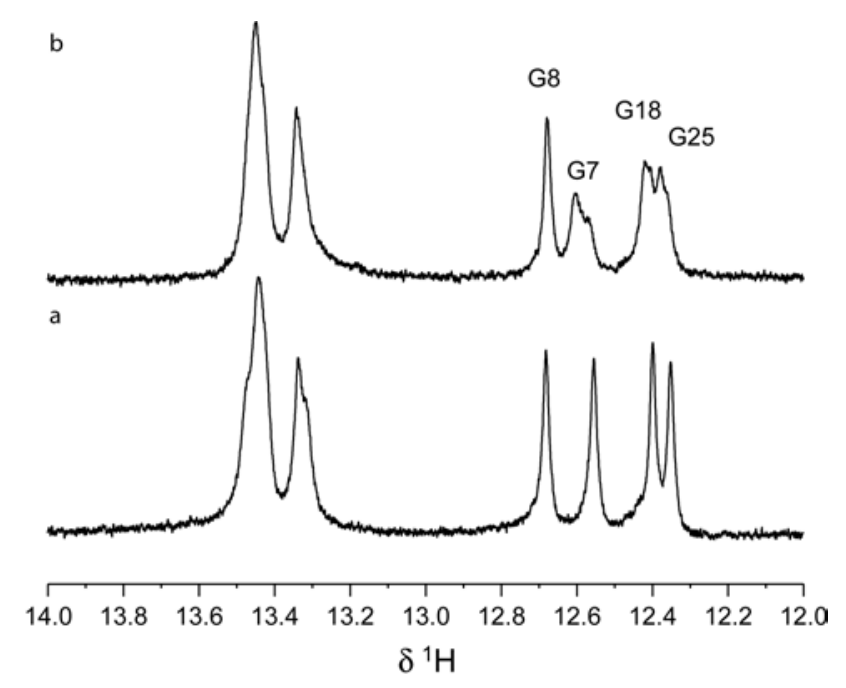

Fig. 1 Comparison of the imino region from the ${ }^{1} \mathrm{H}$ spectra of duplex $\mathrm{I}$ before (a), and immediately after (b), the addition of 1 . The appearance of new peaks associated with the G7, G18 and G25 imino resonances is indicative of the presence of two pre-associated states of $\mathbf{1}$, aligned in both directions along the duplex. 
a
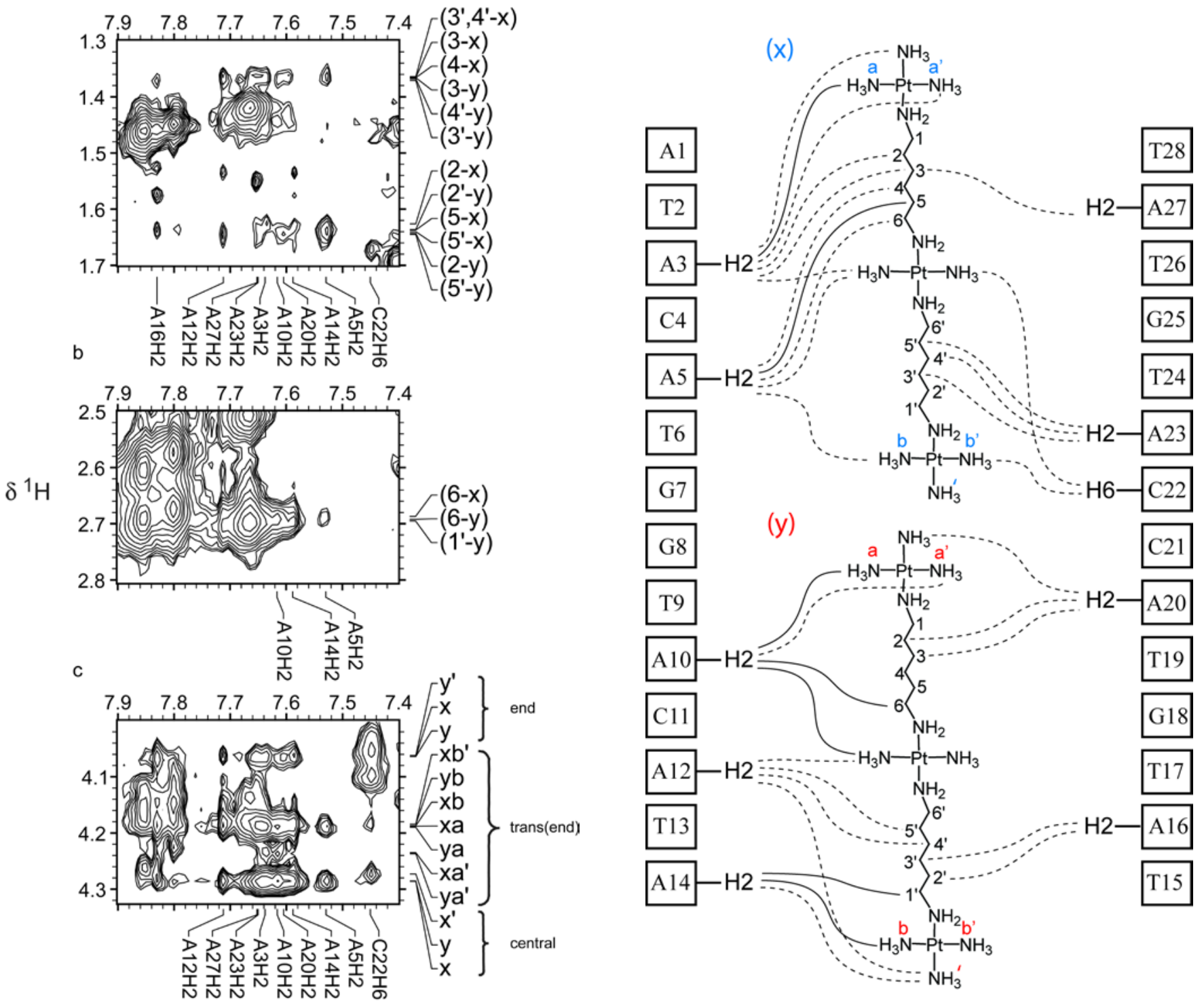

\section{$\delta^{1} \mathrm{H}$}

Fig 2 Portions of the ${ }^{1} \mathrm{H}$ NOESY NMR spectrum ( $298 \mathrm{~K}$ ) of the 2:1 mixture of $\mathbf{O}$ and duplex $I$ showing intermolecular NOEs between the $\mathrm{CH}_{2}(\mathrm{a}$ and $\mathrm{b})$ and $\mathrm{NH}_{3}$ (c) protons of $\mathbf{O}$ and the adenine $\mathrm{H} 2$ protons of the duplex. See Fig. 3 for assignments of the $\mathrm{CH}_{2}$ and $\mathrm{NH}_{3}$ protons of $\mathrm{O}$ in the two preassociated sites ( $x$ and $y$ ).
Fig 3 NOE connectivities obtained from the ${ }^{1} \mathrm{H}$ NOESY NMR spectrum ( 298 $\mathrm{K}$ ) of the 2:1 mixture of $\mathbf{0}$ and duplex $\mathbf{I}$ showing the locations of the two pre-associated molecules ( $x$ and $y$ ). Solid and dashed lines represent strong and medium NOEs, respectively. 

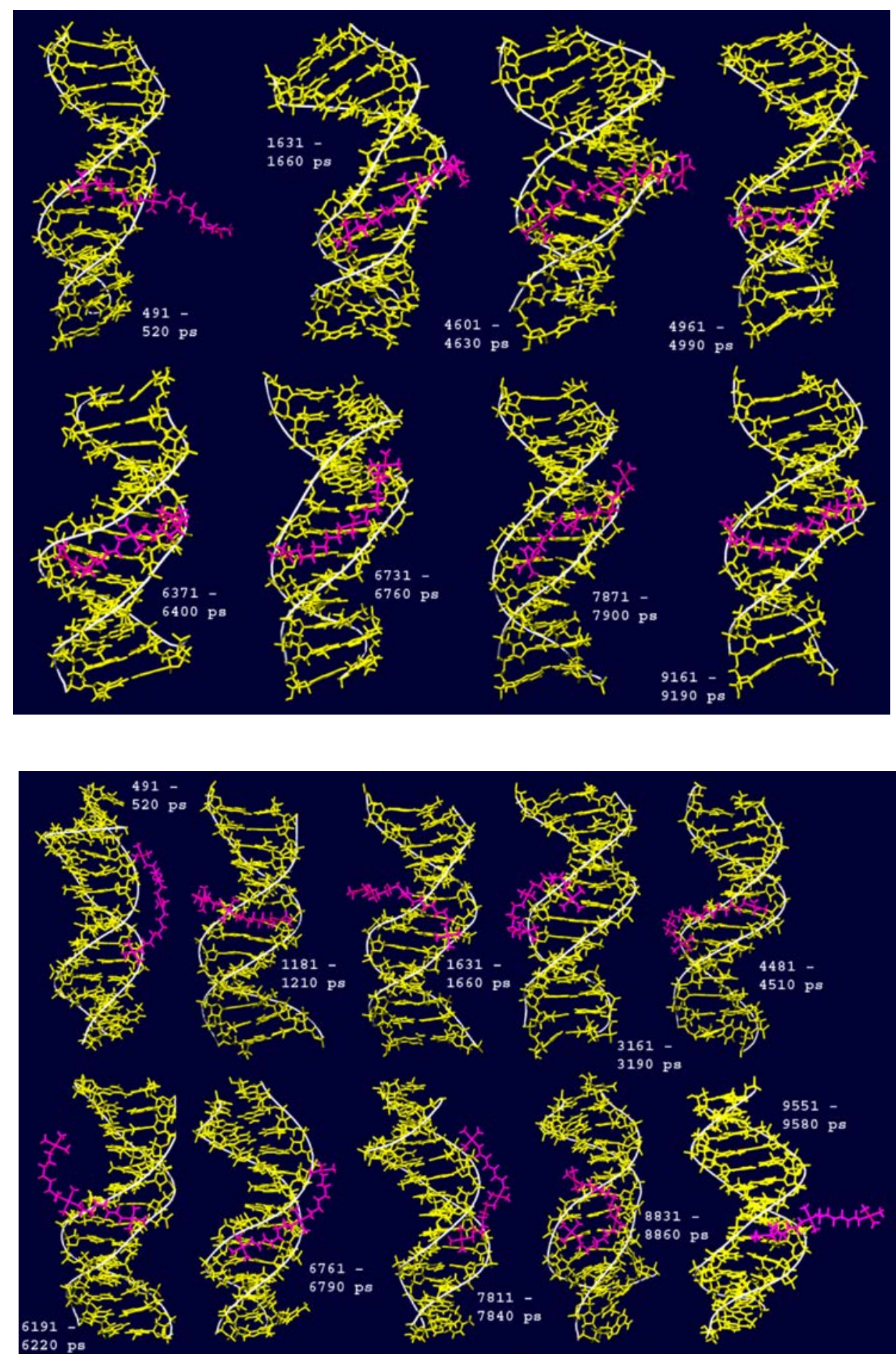

Fig 4 Snapshots of various time points in the production dynamics simulation of $\mathbf{0}$ (non-relativistic DFT Hirshfeld charges) docked at the G18 (top) and G25 (bottom) pre-association sites on duplex I. The energies of the minimised structures from the production dynamics simulation are provided in the supporting information. 
Fig $52 \mathrm{D}\left[{ }^{1} \mathrm{H},{ }^{15} \mathrm{~N}\right] \mathrm{HSQC}$ NMR $(600 \mathrm{MHz})$ spectra at $298 \mathrm{~K}$ of duplex I after reaction with ${ }^{15} \mathrm{~N}-1$ for (a) 2.05, (b) 6.68, (c) 10.25 and (d) $34.58 \mathrm{~h}$. Peaks are assigned to the $\mathrm{NH}_{3}$ and $\mathrm{NH}_{2}$ groups in structures 1-5 (see Scheme 1). Linker refers to the central $\mathrm{PtN}_{4}$ unit of $\mathbf{1}$ while the other identified peaks are attributed to the terminal $\mathrm{Pt}-\mathrm{NH}_{2}$ or $\mathrm{Pt}-\mathrm{NH}_{3}$ groups. "a" and " $\mathrm{b}$ " refer to non-equivalent terminal $\left\{\mathrm{PtN}_{3} \mathrm{Y}\right\}$ groups in non-symmetrical species, where $\mathrm{Y}=\mathrm{Cl}$ (b) and $\mathrm{H}_{2} \mathrm{O}$ or N7-Guanine (a); + represents artefacts associated with very intense cross peaks. 


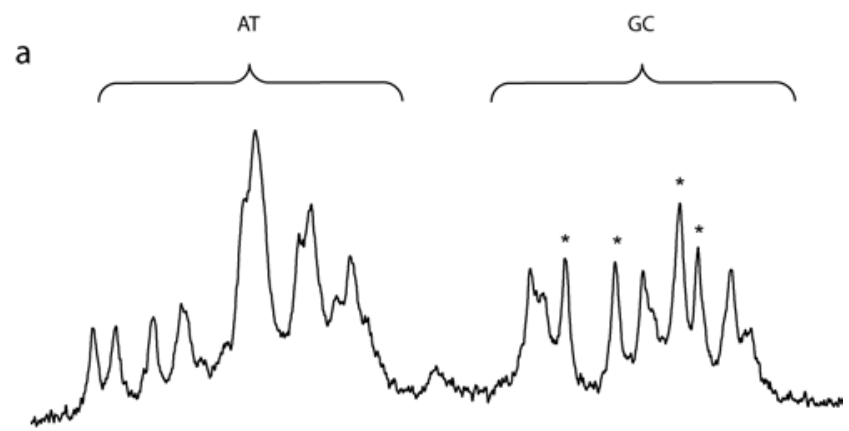

b

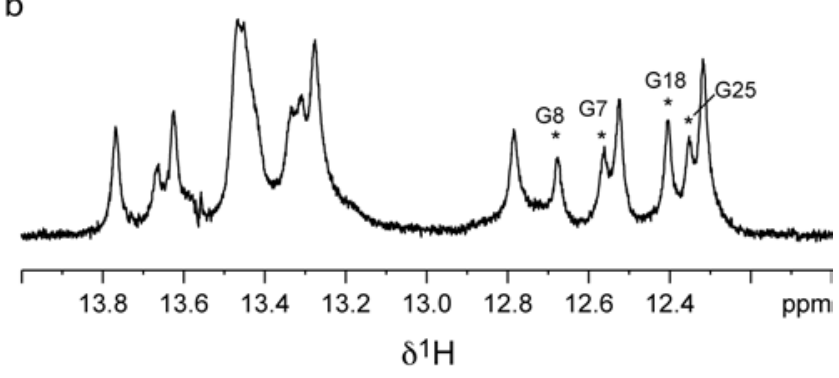

Fig. 6 Comparison of the imino regions of the ${ }^{1} \mathrm{H}$ NMR spectra $(600 \mathrm{MHz})$ of duplex I after completion of the reactions with (a) ${ }^{15} \mathrm{~N}-\mathbf{1}$ and (b) $1,1 / t, t$ (the latter taken from ref. 13). Signals from unplatinated I (resonances for GC base pairs marked ${ }^{*}$ ) are present due to the excess of DNA used in the reactions. 


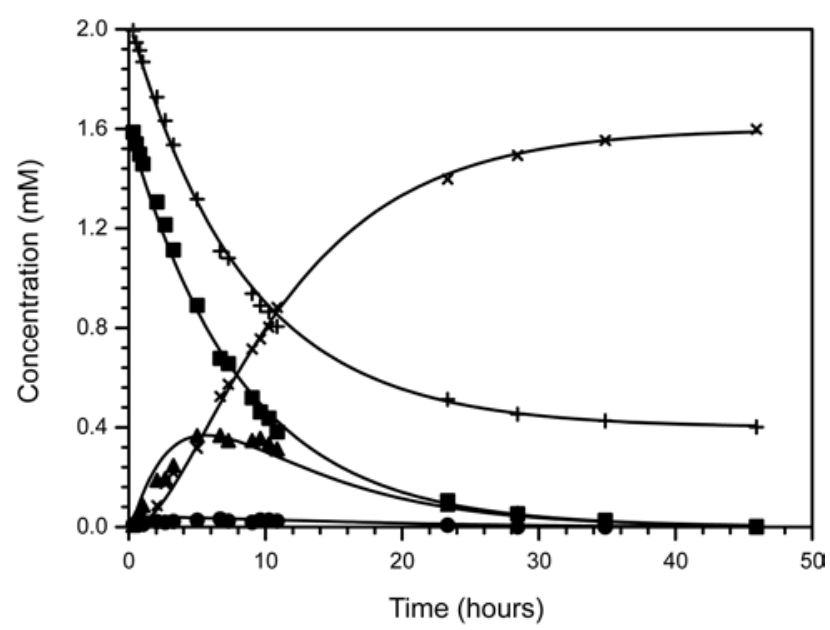

Fig 7 Plot of the relative concentration of species observed during the reaction (at $298 \mathrm{~K}$ ) between $\mathrm{I}$ and ${ }^{15} \mathrm{~N}-\mathbf{1}$, based on the kinetic model shown in Scheme 2. The concentrations are derived from the relative volumes of the terminal Pt- $\mathrm{NH}_{3}{ }^{1} \mathrm{H},{ }^{15} \mathrm{~N}$ peaks (Fig. 5). The curves are computer best fits for the rate constants shown in Table 2. Labels: $\mathbf{1} \mathbf{\square}, \mathbf{2}$ -, combined monofunctional adducts $(3,4) \boldsymbol{\Lambda}$, combined bifunctional adducts (5) $\times$, duplex I + (see Scheme 1 ). 